\title{
BIOLOGIA E ONTOGENIA DE TRACHYDERES STRIATUS (FABRICIUS) (COLEOPTERA, CERAMBYCIDAE)
}

\author{
Angélica Maria Penteado-Dias ${ }^{1}$
}

\begin{abstract}
In this paper larval and pupal stages of Trachyderes striatus (Fabricius) are described. Some aspects of its biology are added.

O presente trabalho é um estudo da morfologia das formas imaturas de Trachyderes striatus, comparando-as com aquelas de outras espécies do gênero e acrestentando dados sobre a sua biologia.

O material procede de São Carlos, SP e foi identificado por Ubirajara R. Martins do Museu de Zoologia da Universidade de São Paulo, a quem agradeço. Larvas e pupas conservadas em solução de Dietrich foram desenhadas sob lupa e microscópio com câmara clara.
\end{abstract}

\section{LARVA}

(Figs. 1 - 18)

Comprimento Total: $30 \mathrm{~mm}$; comprimento do protórax: $4,0 \mathrm{~mm}$; largura do protórax: $8,0 \mathrm{~mm}$.

Forma cilíndrica, o protórax sendo o segmento mais largo.

Cabeça (Figs. 1 - 2) com margem anterior da fronte quitinizada; foramem occipital dividido; porção anterior menor; sutura mediana evidente; suturas frontais indistintas; apenas duas cerdas epistomais distintas; margem do hipóstoma denteada. Antena (Figs. 3-16) triarticulada, processo suplementar com 1/3 do comprimento do segmento III. Um ocelo de cada lado, nítido, não pigmentado (Fig. 4).

Mandíbulas (Figs. 6 - 7) oblíquas lateralmente e com cerdas.

Lobo maxilar ( $\mathrm{Fig}$. 8) com muitas cerdas, atinge a margem superior do segmento I do palpo maxilar, este com três artículos, o terceiro com o ápice microtuberculado (Figs. 9 - 10). Palpífero com processo dorso-esternal pouco evidente (Fig. 11). Lábio com mento muito mais longo que largo, estipe ligeiramente emarginada anteriormente; palpos labiais com cerdas longas no primeiro artículo e algumas proję̧бes no ápice do segundo (Fig. 12). Labro como na Figura 13.

Pronoto (Fig. 14), mesonoto e matanoto com cerdas brilhantes e abundantes. Região anterior do pronoto com faixa transversal, levemente quitinizada, de cor castanha-clara. Posteriormente há uma leve rugosidade com cerdas esparsas. Dobra pós-notal, sulcos laterais e linha média de clivagem distintos.

Prosterno (Fig. 15) com presterno, eusterno e esternelo definidos; esternelo com

1 Departamento de Ciências Biológicas, Universidade Federal de São Carlos, Cx. Postal 384, 13560 - São Carlos, SP. 
algumas cerdas, eusterno glabro.

Sulcos laterais do pronoto e do prosterno sem as "manchas quitinizadas" citadas para T. thoracicus por Penteado-Dias (1980).

Pernas (Fig. 5) com quatro segmentos; unguículo flageliforme.

Espiráculo mesotorácico oval, maior que os abdominais. Segmentos abdominais com tubérculos pleurais igualmente desenvolvidos; região das ampolas glabra (Figs. 17 - 18). Todos os segmentos abdominais com cerdas brilhantes esparsamente distribuídas.

Segmentos abdominais VIII-X sem ampolas dorsais ou ventrais; IX e X sem espiráculos evidentes. Ânus trilobado.

\section{PUPA 9}

(Figs. 19 - 20)

Comprimento total : $21 \mathrm{~mm}$; comprimento do protórax: $4,5 \mathrm{~mm}$; largura do protórax: $5,0 \mathrm{~mm}$.

Cabeça ligeiramente triangular com vértice levemente deprimido entre os tubérculos anteníferos que são poucos salientes. Mandíbulas glabras; labro subcordiforme, glabro e com depressão longitudinal mediana. Antenas longas atingindo o tergito abdominal IV e voltando-se anteriormente até a altura do tergito II.

Protórax com bordos laterais sinuosos; pronoto corrugado, com tubérculos providos de cerdas esparsas. Sulco escutelar coberto pelo escutelo que é bem desenvolvido, quase atingindo a margem posterior do metanoto. Processo prosternal não ultrapassa posteriormente as coxas anteriores; processo mesosternal alargado.

Ápices dos élitros acuminados, atingindo o segmento abdominal III.

Pernas lisas, ápices dos fêmures posteriores alcançam a margem posterior do segmento abdominal IV; ponta das tíbias anteriores, medianas e posteriores com duas projeções espinhosas.

Urosternitos glabros; tergitos com espinhos e cerdas evidentes. Espiráculos ovais, pigmentados e bem evidentes nos segmentos I-V; pouco evidentes e não pigmentados nos segmentos VI-VII.

\section{BIOLOGIA}

(Figs. 21 - 24)

Segundo Duffy (1960), outros autores já se referiram à biologia desta espécie: Bosq (1942); Hayward (1941); Lima (1922, 1928); Reed (1912); Trujillo (1942) e Wille (1925).

Pela primeira vez, a planta hospedeira citada para $T$. striatus é Delonix sp. Os ovos são postos sobre a casca e região cortada. Eles têm aproximadamente $1,8 \mathrm{~mm}$ por $0,8 \mathrm{~mm}$, são postos em grupos e cobertos pela fêmea com pó de serragem, ficando assim camuflados.

O tempo de desenvolvimento do ovo é de quatro dias. As larvas recém eclodidas medem 1,0 $\mathrm{mm}$ de comprimento com protórax de $0,7 \mathrm{~mm}$ de largura. Têm um par de ocelos pigmentados; antenas bissegmentadas e com cerdas; labro com poucas cerdas; palpo maxilar com três segmentos, o apical maior e com cerdas no ápice; lobo maxilar arredondado, com cerdas no ápice e na altura do segmento III do palpo maxilar. 


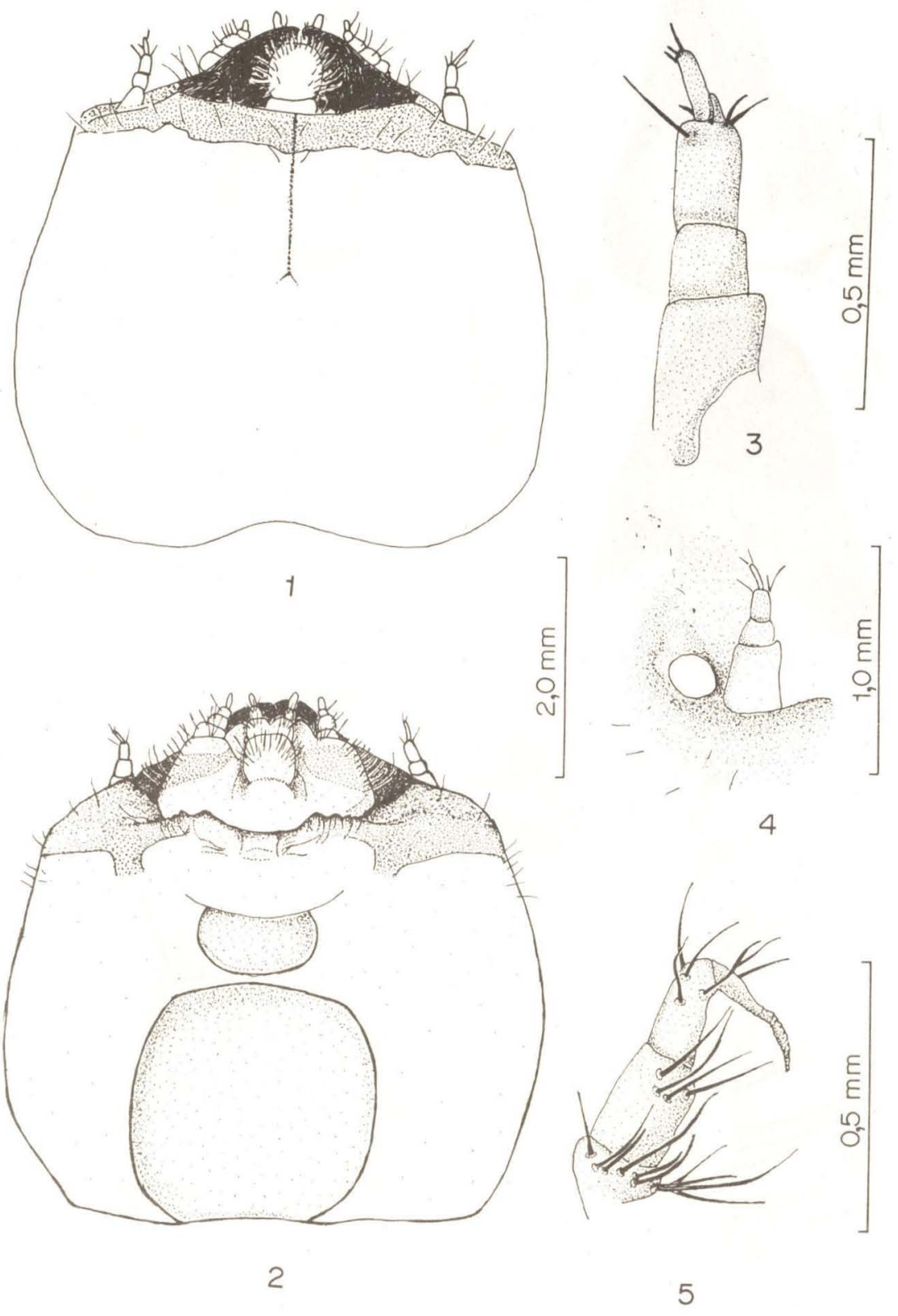

Trachyderes striatus, larva: 1 , cabeça (dorsal); 2 , cabeça (ventral) ; 3 , antena; 4 , posição do ocelo em relação à antena; 5 , perna. 


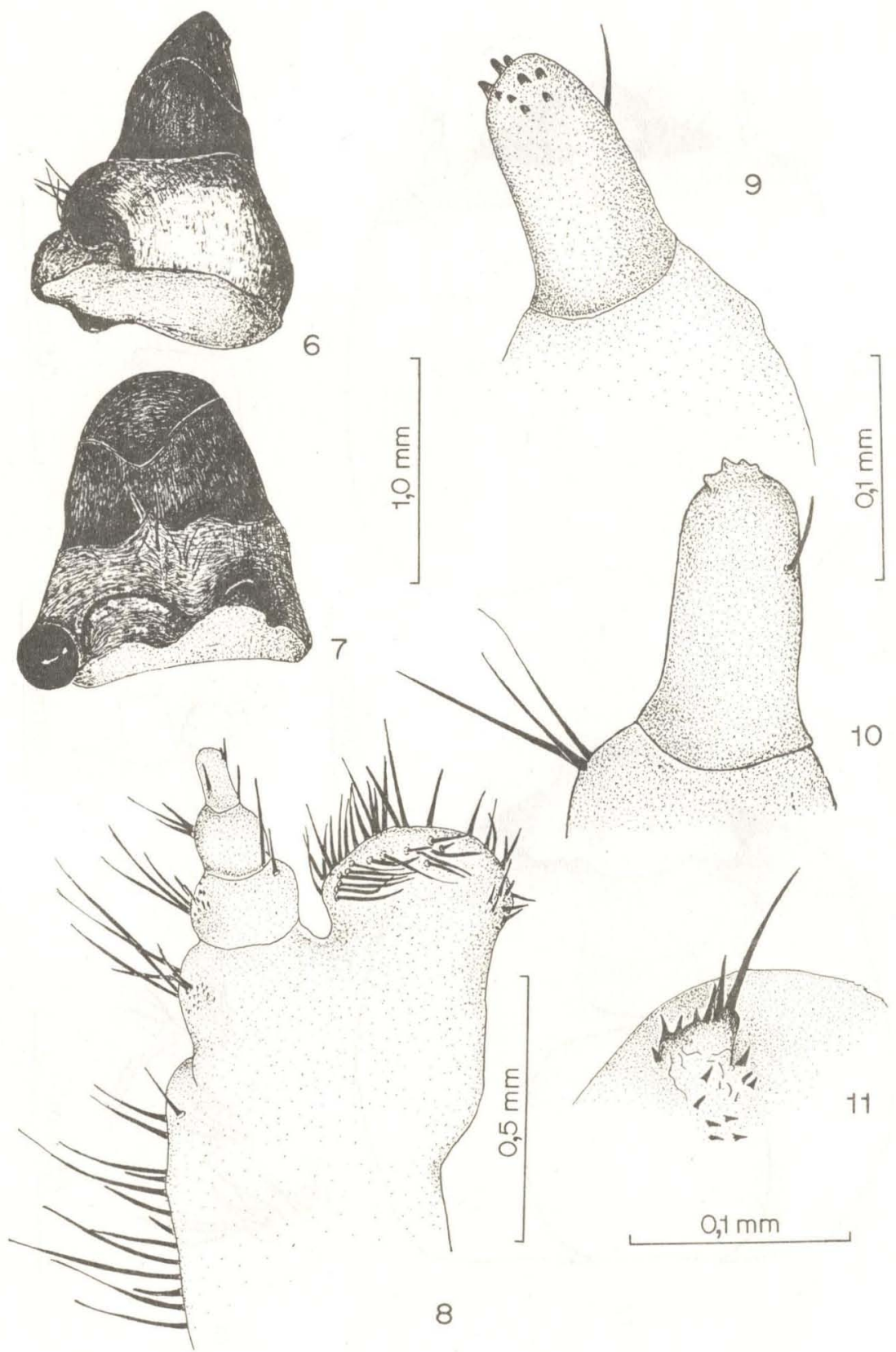

Trachyderes striatus, larva: $6 ; 7$, mandíbulas; 8 . maxila; $9 ; 10$, segmento III do palpo maxilar; 11 , processo dorso-esternal. 


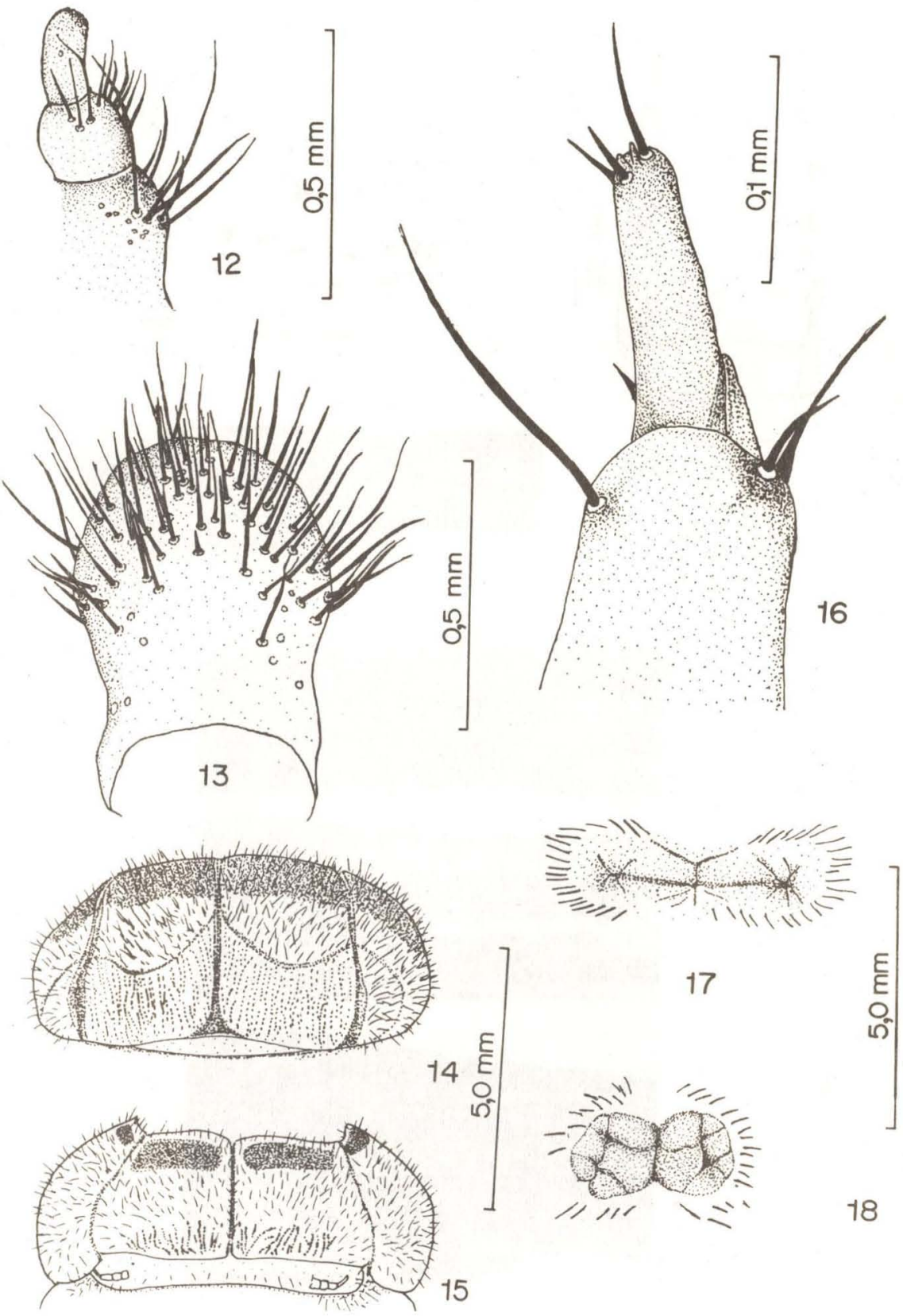

Trachyderes striatus, larva: 12, palpo labial; 13, labro; 14, pronoto; 15 , prosterno; 16 , antena (detalhe); 17-18, ampolas abdominais (17, primeira dorsal; 18 , última dorsal). 

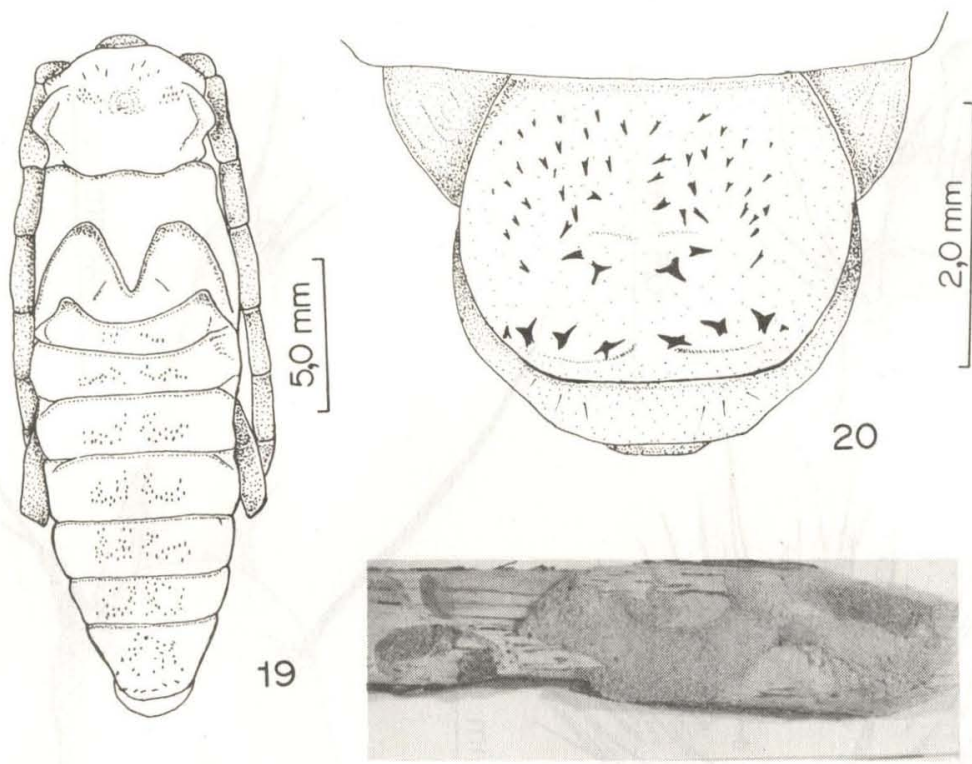

21
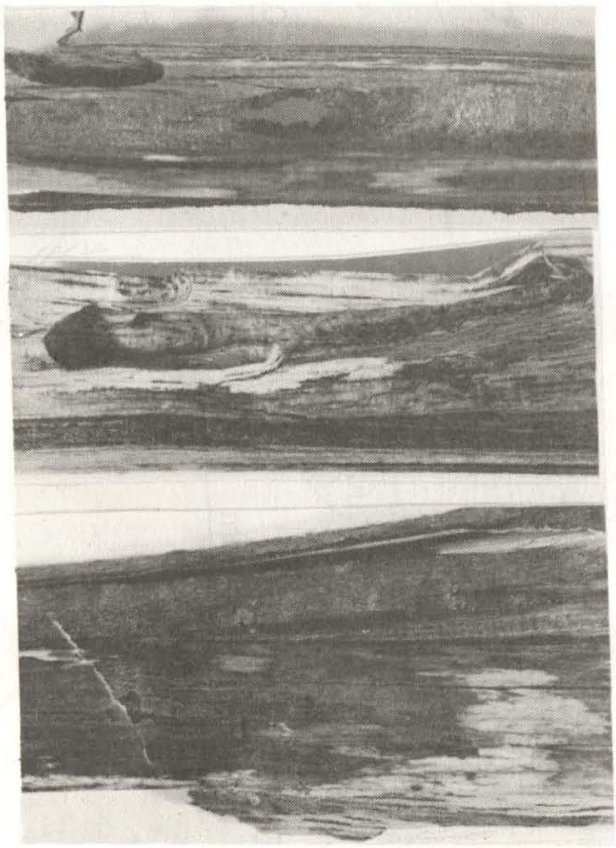

Trachyderes striatus, pupa: 19 ; $\$$ (dorsal); 20 , últimos segmentos, $\$$ (dorsal). Biologia : 21, galerias larvais; $22 ; 23$, câmaras pupais; 24 , orifícios de emergência. 
Pronoto com cerdas, principalmente na margem anterior.

Espiráculos simples, bem visíveis nos útlimos segmentos. Próximo à cada espiráculo são evidentes duas cerdas e um espinho.

A partir de ovos postos em novembro de 1983, obtiveram-se pupas em julho de 1984.

As galerias larvais (Fig. 21) medem aproximadamente $5 \mathrm{~mm}$ de largura; as câmaras pupais (Figs. 22 - 23) são longitudinais em relação ao maior eixo do ramo, medindo aproximadamente $50,5 \mathrm{~mm}$ de comprimento, $6 \mathrm{~mm}$ de largura e $10 \mathrm{~mm}$ de altura. Orifícios de emergência (Fig. 24) arredondados, com luz de aproximadamente $3 \mathrm{~mm}$ de diâmetro.

\section{CONSIDERAÇÕES TAXONOMICAS}

O tempo decorrido da oviposição à eclosão é aproximadamente igual ao de $T$. thoracicus (quatro dias) e menor que em $T$. succinctus (6 - 8 dias).

A larva de $T$. striatus é bastante semelhante à de $T$. thoracicus descrita por Penteado-Dias (1980) desta diferindo por: margem frontal do hipóstoma com os dois dentes laterais à gula um pouco menos pronunciados; ampolas ventrais abdominais sem placa esclerozada e estriada; sulcos laterais do pronoto e prosterno sem "manchas quitinizadas".

A larva de $T$. succinctus descrita por Duffy (1960) tem apenas um par de dentes, um de cada lado da gula; palpo maxilar com segmento III ligeiramente maior que o II; eusterno não distinto; ampolas ventrais abdominais com placa esclerozada e estriada.

Pupas de $T$. striatus com tubérculos sobre o pronoto em número e forma diferentes daqueles de $T$. thoracicus. Tergito VIII com menor número de espinhos que em $T$. succinctus e $T$. thoracicus. 0 tamanho da pupa é menor que o de $T$. thoracicus e T. succinctus.

O ciclo completo (ovo-adulto) é mais longo (oito meses) que o de $T$. succinctus (cinco meses).

\section{REFERENCIAS}

Duffy, E.A.J.1960. A monograph of the immature stages of Neotropical timber beetles (Cerambycidae). VII, 327pp., British Museum (Nat. Hist.). London.

Penteado-Dias, A.M.1980. Contribuição ao conhecimento da biologia e ontogenia de Thachyderes thoracicus (Olivier, 1979) (Coleoptera, Cerambycidae). Rev. bras. Ent. 24(2):131-136. 